\title{
Oxygen content-related DNA damage of graphene oxide on human retinal pigment epithelium cells
}

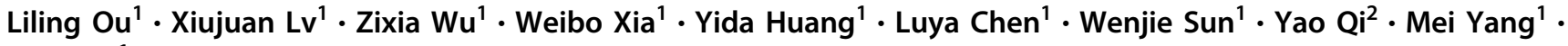 \\ Lei Qi ${ }^{1}{ }^{1}$
}

Received: 5 November 2020 / Accepted: 4 February 2021 / Published online: 27 February 2021

(c) The Author(s) 2021

\begin{abstract}
Arguments regarding the biocompatibility of graphene-based materials (GBMs) have never ceased. Particularly, the genotoxicity (e.g., DNA damage) of GBMs has been considered the greatest risk to healthy cells. Detailed genotoxicity studies of GBMs are necessary and essential. Herein, we present our recent studies on the genotoxicity of most widely used GBMs such as graphene oxide (GO) and the chemically reduced graphene oxide (RGO) toward human retinal pigment epithelium (RPE) cells. The genotoxicity of GO and RGOs against ARPE-19 (a typical RPE cell line) cells was investigated using the alkaline comet assay, the expression level of phosphorylated p53 determined via Western blots, and the release level of reactive oxygen species (ROS). Our results suggested that both GO and RGOs induced ROS-dependent DNA damage. However, the DNA damage was enhanced following the reduction of the saturated C-O bonds in GO, suggesting that surface oxygen-containing groups played essential roles in the reduced genotoxicity of graphene and had the potential possibility to reduce the toxicity of GBMs via chemical modification.
\end{abstract}

\section{Graphical Abstract}

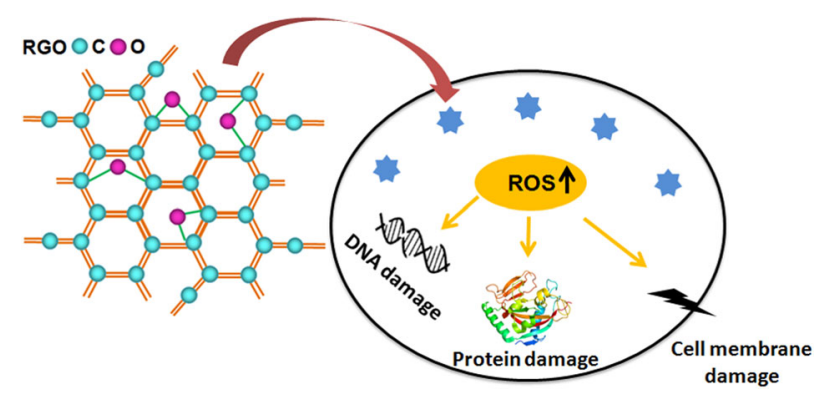

These authors contributed equally: Liling Ou, Xiujuan Lv, Zixia Wu

Supplementary information The online version contains supplementary material available at https://doi.org/10.1007/s10856021-06491-0.

Yao Qi

qiyao914@163.com

Mei Yang

meiyang112686@wmu.edu.cn

$\triangle$ Lei Qi

imdoll@163.com

\section{Introduction}

Graphene-based materials (GBMs) possess a large active surface area for substance transportation by taking advantage because of their unique one-atom thickness and twodimensional plane, which are favorable for applications in areas of disease therapy and diagnostics such as biosensing,

1 State Key Laboratory of Ophthalmology, Optometry and Visual Science, Institute of Advanced Materials for Nano-Bio Applications, School of Ophthalmology and Optometry, School of Biomedical Engineering, Wenzhou Medical University, Wenzhou, China

2 Department of Ultrasonic, The First Hospital of Qiqihar, Affiliated Qiqihar Hospital, Southern Medical University, Qiqihar, China 
drug delivery, and tissue engineering [1-3]. Graphene oxide (GO) which is the most important initial molecular unit of the GBMs, is generally thought to be compatible for biological applications due to its hydrophilic functional groups [4]. Similar to other research groups' works on cytotoxicity of GO [5, 6], we have found out that oxygen-containing functional groups modified graphene prepared from both chemical oxidation and edge-functionalized ball milling method exhibited good biocompatibility with ocular cells and tissues [7, 8]. However, despite of numerous efforts, no accordance has been reached regarding the safety of GO, in considering the size-, concentration dependent or various cell strains [8-11]. Moreover, the oxidation degree of the $\mathrm{GO}$ is also an inevitable indicator of the safety of GO on biological organisms.

A number of studies have focused on the biological effects of GO and reduced GO (RGO) on mammalian cells $[12,13]$. Two distinct points have been proposed. In the Das et al. study, RGOs that were reduced by the hydrazine hydrate method, were found to be safer than GO on human umbilical vein endothelial cells (HUVECs). They hypothesized that more reactive functional groups (e.g., $-\mathrm{OH}$, $-\mathrm{COOH})$ of $\mathrm{GO}$ potential to interact with the macromolecules than in RGO and enhancing the bio-nano interaction dependent toxicity [12]. However, Zhang et al. prepared RGOs by reducing the amount of $\mathrm{KMnO}_{4}$ used during hummer's method. These RGOs exhibited a higher degree of cytotoxicity and apoptosis as the degree of oxidation decreased. They found that the less oxidized GO produced a higher level of reactive oxygen species (ROS) and induced the oxidative damage [13]. Researchers have also found that both GO and RGO solid substrates are compatible with NIH-3T3 fibroblast [14]. This discrepancy inspired us to investigate the mechanisms of oxidation-state dependent cytotoxicity of GO.

In addition, GO is readily transported across the cell membrane [7], because of its unique size and morphology, resulting in the destruction of biomolecules such as nucleic acids, lipids, and proteins. This may cause unpredictable genotoxicity of GO which has also attracted intense attention. Though we have reported mild genotoxicity against human retinal pigment epithelium (RPE) cells for hydroxylfunctionalized graphene $(\mathrm{G}-\mathrm{OH})$ at the concentration up to $100 \mu \mathrm{g} / \mathrm{mL}$, which synthesized by ball milling [7]. Detailed genotoxicity studies of GOs with different oxidation-states on ocular cells, such as RPE cells are needed and worthwhile since the risk of eye contamination by GO for people, who work in the fields of graphene production, transportation, research, and biomedical applications, is very high. In this work, RGOs were prepared by Na-citrate reduction and the RGOs with different oxidation states were obtained by controlling the reduction time. GO displayed much better cytotoxicity than RGOs. Furthermore, we measured the genotoxicity of GO compared to RGOs against ARPE-19 cells by means of alkaline Comet assay for DNA damage, Western blotting for the detection of phosphorylated p53 expression, and ROS generation. Though ROS-dependent DNA damage caused by both GO and RGOs was observed, the genotoxicity of the RGOs was much stronger than that of GO. The lower oxygen content led to stronger genotoxicity, suggesting a possible relationship between the oxygen content and genotoxicity of GBMs.

\section{Materials and methods}

\subsection{Preparation of graphene oxide (GO)}

GO was prepared via a modified Hummer's method. Typically, graphite was oxidized in mixed oxidant of $\mathrm{H}_{2} \mathrm{SO}_{4}, \mathrm{NaNO}_{3}, \mathrm{KMnO}_{4}$, and $30 \%$ (w/w) $\mathrm{H}_{2} \mathrm{O}_{2}$ for $2 \mathrm{~h}$. The solid mixture was then collected after centrifugation. A mixed solution of $3 \%(\mathrm{w} / \mathrm{w}) \mathrm{H}_{2} \mathrm{SO}_{4} / 0.5 \%$ (w/w) $\mathrm{H}_{2} \mathrm{O}_{2}$ was then used to wash the mixture and exfoliate the graphite oxide using ultrasonication for $30 \mathrm{~min}$. DI water was further used to rinse and exfoliate the nanosheets via ultrasonication over $2 \mathrm{~h}$.

\subsection{Preparation of reduced graphene oxide (RGO)}

RGOs were prepared via a "green" reduction approach with the use of Na-citrate. Typically, $0.05 \mathrm{mg}$ Na-citrate was added to the GO dispersion $(25 \mu \mathrm{g} / \mathrm{mL})$ with a final volume of $40 \mathrm{~mL}$. The reactions were carried out in polytetrafluoroethylene reaction kettles at $100{ }^{\circ} \mathrm{C}$ for 3,6 , 9, and $12 \mathrm{~h}$. The corresponding reduced products were named RGO-3, RGO-6, RGO-9, and RGO-12. The resulting samples were then centrifuged at $8000 \mathrm{rpm}$ for $10 \mathrm{~min}$. The as-synthesized supernatants were subsequently transferred into D.I. $\mathrm{H}_{2} \mathrm{O}$ until the $\mathrm{pH}$ value was to 5.5. Another of $30 \mathrm{~min}$ ultrasonication was produced at $100 \mathrm{~W}$ just before the biocompatibility assays.

\subsection{Characterization}

The GO and RGO samples were characterized using UV-visible spectrophotometry (UV-Vis, Agilent Cary 100), Fourier transform infrared spectroscopy (FTIR, Thermo Nicolet 6700), X-ray photoelectron spectroscopy (XPS), transmission electron microscopy (TEM), and atomic force microscopy (AFM).

\subsection{Cell culture}

Human RPE cells (ARPE-19) were cultured in DMEM/F12 (Gibco) supplemented with 10\% (v/v) qualified Fetal 
Bovine Serum (Gibco) and gentamicin $(50 \mu \mathrm{g} / \mathrm{mL}$, Gibco) at $37{ }^{\circ} \mathrm{C}$ with $10 \% \mathrm{CO}_{2}$.

\subsection{Cell viability}

Cell Counting Kit-8 (CCK-8, Dojindo) was used to determine the cell viability. The cells were seeded in 96 -well plates at a density of 3000 cells/well and preincubated for $24 \mathrm{~h}$. The cells were cultured with GO or RGOs at various concentrations (10, $50,100,200 \mu \mathrm{g} / \mathrm{mL}$ ). Cells cultured in medium without the addition of GO or RGOs were used as the negative control. After $6,12,24,48$, and $72 \mathrm{~h}$ of incubation, the culture medium was replaced with $100 \mu \mathrm{L}$ of CCK-8 solution diluted in culture medium at a ratio of $1: 10(\mathrm{~V} / \mathrm{V})$ and incubated for an additional $3 \mathrm{~h}$ at $37^{\circ} \mathrm{C}$. The optical density (OD) of each well at $450 \mathrm{~nm}$ was recorded by means of a SpectraMax M5 (Molecular Devices). The cell viability was expressed as the percentage of $\left(\mathrm{OD}_{\text {test }}-\mathrm{OD}_{\text {blank }}\right) /\left(\mathrm{OD}_{\text {negative }}-\mathrm{OD}_{\text {blank }}\right)$, where $\mathrm{OD}_{\text {blank }}$ is the optical density of culture medium without ARPE-19 cells.

Calcein-AM/PI staining (Dojindo) was further used for the direct observation of living/dead cells. The cells were cultured in 24-well plates at a density of 30,000 cells per well. After $24 \mathrm{~h}$, the cell medium was changed to fresh medium with GO or RGOs $(200 \mu \mathrm{g} / \mathrm{mL})$ for $72 \mathrm{~h}$. The cells were dyed with the staining solution for $15 \mathrm{~min}$ and observed under a fluorescence microscope (OLYMPUS IX81) with green/red fluorescent exciters (Ex/Em of Calcein-AM: 490/515; Ex/Em of PI: 535/617).

\subsection{Reactive oxygen species (ROS) assay}

The cells were seeded in 96-well black plates (Clear bottom, Costar 3603) at 10,000 cells per well and preincubated for $24 \mathrm{~h}$. The cells were cultured with various concentrations of GO or RGOs $(10,50,100,200 \mu \mathrm{g} / \mathrm{mL})$ for $6,12,24,48$, and $72 \mathrm{~h}$. The oxidant-sensitive dye DCFH-DA was used for ROS detection (Reactive Oxygen Species Assay Kit, Beyotime Institute of Biotechnology, China). The culture medium for all cells were replaced by $100 \mu \mathrm{L}$ of new culture medium (without supplementation of Fetal Bovine Serum) containing $10 \mu \mathrm{M}$ DCFH-DA for $20 \mathrm{~min}$ at $37^{\circ} \mathrm{C}$ in the dark. The cells were washed with culture medium (without supplementation of Fetal Bovine Serum) for three times. The positive control was prepared by culturing normal cells with culture medium containing $500 \mathrm{mM} \mathrm{H}_{2} \mathrm{O}_{2}$ for $30 \mathrm{~min}$ after the cells were labeled by DCFH-DA, while the negative control was the normal culture medium without the addition of nanomaterials. The fluorescence intensity was detected by means of a SpectraMax M5 (Molecular Devices) with an excitation wavelength of $488 \mathrm{~nm}$ and an emission wavelength at $525 \mathrm{~nm}$ in the mode of bottom read mode. The ROS level was expressed as the ratio of $\left(I_{\text {test }}-\right.$ $\left.I_{\text {blank }}\right) /\left(I_{\text {negative }}-I_{\text {blank }}\right)$, where $I_{\text {blank }}$ is the fluorescence intensity of the culture medium without the cells. The cells incubated with GO or RGOs at $200 \mu \mathrm{g} / \mathrm{mL}$ for $72 \mathrm{~h}$ were further observed by fluorescence microsccopy with green fluorescent excitation.

\subsection{Alkaline Comet assay}

An alkaline comet assay reagent kit (TREVIGEN) was used to evaluate DNA damage, including single- and doublestranded breaks in cells. The cells were grown on polystyrene six-well tissue culture plates (Corning) at a density of 200,000 cells per well and preincubated for $24 \mathrm{~h}$. The cells were continuously cultured in an incubator with $100 \mu \mathrm{g} / \mathrm{mL}$ of GO or RGOs for $24 \mathrm{~h}$. Cells cultured in the medium with $0.5 \mathrm{M} \mathrm{H}_{2} \mathrm{O}_{2}$ for 10 min were used as the positive control, while cells incubated without the addition of nanomaterials were used as the negative controls [15]. DNA was visualized by staining with the fluorescent DNA binding dye PI and observed by a fluorescence microscope (OLYMPUS, IX81). The percent of DNA in the tail was calculated by the software of Comet Assay Software Project.

\subsection{Western blot}

The cells were grown on polystyrene six-well tissue culture plates at a density of $2.5 \times 10^{5}$ cells/well and preincubated for $24 \mathrm{~h}$. The cells were continuously cultured with the addition of GO or RGOs $(100 \mu \mathrm{g} / \mathrm{mL})$ for $24 \mathrm{~h}$. Cells cultured in the medium with no addition of nanomaterials were used as the negative control. The cells were harvested and lysed in western cracking buffer (Beyotime) for $5 \mathrm{~min}$. The total protein solutions were collected by centrifugation at $14,000 \mathrm{rpm}$ for $15 \mathrm{~min}$ and concentrated by an Amicon ultra centrifugal filter (Millipore, $0.5 \mathrm{~mL}$, $10 \mathrm{kDa})$ at $4{ }^{\circ} \mathrm{C}$. The concentrations of protein were determined by the BCA Protein Assay Kit (Thermo). Western blotting was used to analyze the phosphorylated p53 (pi-p53) expression level by probing with a phosphorylated p53-Ser15 rabbit polyclonal antibody (Abcam). The samples were blotted with Goat Anti-Rabbit IgG H\&L (HRP) secondary antibodies (Abcam) after incubation with primary antibody. The GAPDH was used as the loading control probe with a HRP-anti-GAPDH monoclonal antibody (KANGCHEN). A chemiluminescent substrate kit (SuperSignal West Dura Extended Duration Substrate, Thermo) was used for HRP detection on the immunoblots. The relative band intensities (according to the band of GAPDH) were calculated by the software of Image Lab (Bio-Rad Laboratories). 


\subsection{Statistical analysis}

Six parallel tests were conducted for each practical type. Significance was calculated using unpaired two-tailed Student's t-test with unequal variance used for statistical analysis. "**" denotes statistical significance $(* \leq 0.05, * * \leq 0.01$, $* * * \leq 0.001)$ vs. the control.

\section{Results}

\subsection{Characterization of RGOs}

Biocompatible Na-citrate was used as the reductant for the preparation of RGOs to minimize the influence of the reductant on the biocompatibility of RGOs. The reduction of GO was characterized by using different spectroscopies such as UV-Vis, FTIR, and XPS. Two characteristic peaks of GO were observed in the UV-Vis spectra, corresponding to $\mathrm{C}=\mathrm{C}(231 \mathrm{~nm})$ and $\mathrm{C}=\mathrm{O}(300 \mathrm{~nm})$ (Fig. 1A). A bathochromic shift of the peak at $231 \mathrm{~nm}$ and the disappearance of the band at $300 \mathrm{~nm}$ were observed in the spectrum of sample RGO-3, suggesting the successful reduction of $\mathrm{C}=\mathrm{O}$. Similar $\mathrm{UV}-\mathrm{Vis}$ results were observed for samples RGO-6, RGO-9, and RGO-12, confirming the reduction in oxygen contents in the RGOs. In the FTIR spectra (Fig. 1B), two typical peaks at $1726 \mathrm{~cm}^{-1}$ and $1081 \mathrm{~cm}^{-1}$, attributed to the $\mathrm{C}=\mathrm{O}$ and $\mathrm{C}-\mathrm{O}$, were not present in the spectra of RGO-3, RGO-6, RGO-9, and RGO-12, which was consistent with the UV-Vis measurements. The oxidation states were further confirmed by XPS (Fig. $1 \mathrm{C}-\mathrm{H}$ ), where the relative intensities of the $\mathrm{C}-\mathrm{O}$ $(286.5 \mathrm{eV})$ and $\mathrm{C}=\mathrm{O}(287.1 \mathrm{eV})$ peaks decreased in the spectra of the RGOs versus that of GO. As shown in Fig. $1 \mathrm{H}$, the mass ratio of carbon to oxygen $(\mathrm{C} / \mathrm{O})$ for the RGOs decreased with increasing reduction time.

The morphologies of GO and RGOs were measured by using TEM and AFM (Fig. 2). Typical transparent, flakeshaped nanosheets were observed in the TEM images of GO and RGOs (Fig. 2A-E). The corresponding AFM images exhibited an average thickness of $\sim 1.4 \pm 0.2 \mathrm{~nm}$ for GO and RGOs (Fig. 2F-J), suggesting that chemical
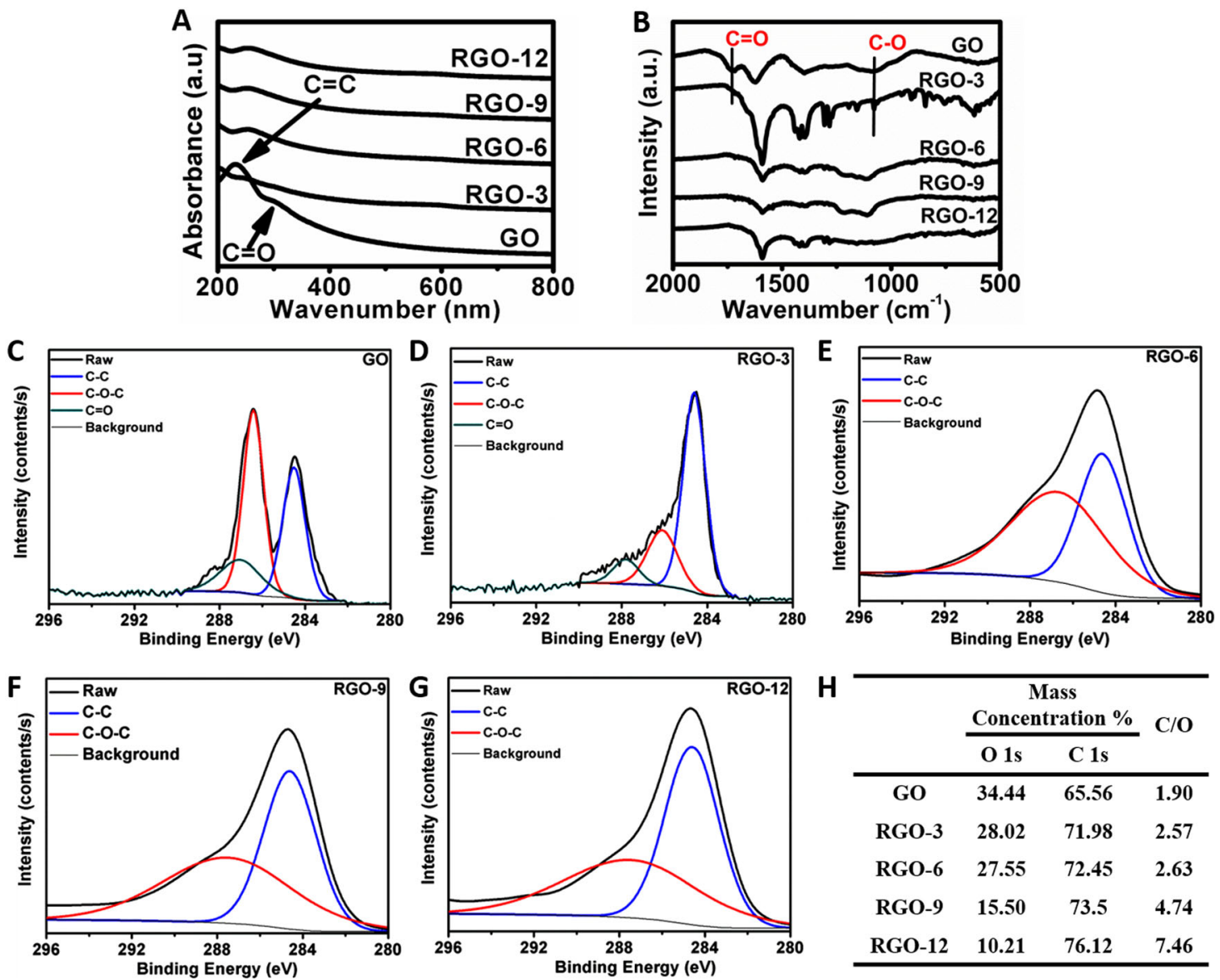

Fig. 1 Characterization results of RGOs compared to GO using A UV-Vis spectra and B FTIR spectra. The XPS high-resolution C1s spectrum of GO (C), RGO-3 (D), RGO-6 (E), RGO-9 (F), RGO-12
(G) and the mass ratio of carbon to oxygen (C/O) in the GO and RGOs determined by XPS (H) 
Fig. 2 TEM micrographs of GO and RGOs ((A-E), the scales were $100 \mathrm{~nm})$; AFM micrographs of GO and RGOs $((\mathbf{F}-\mathbf{J})$, the scales were $1 \mu \mathrm{m})$
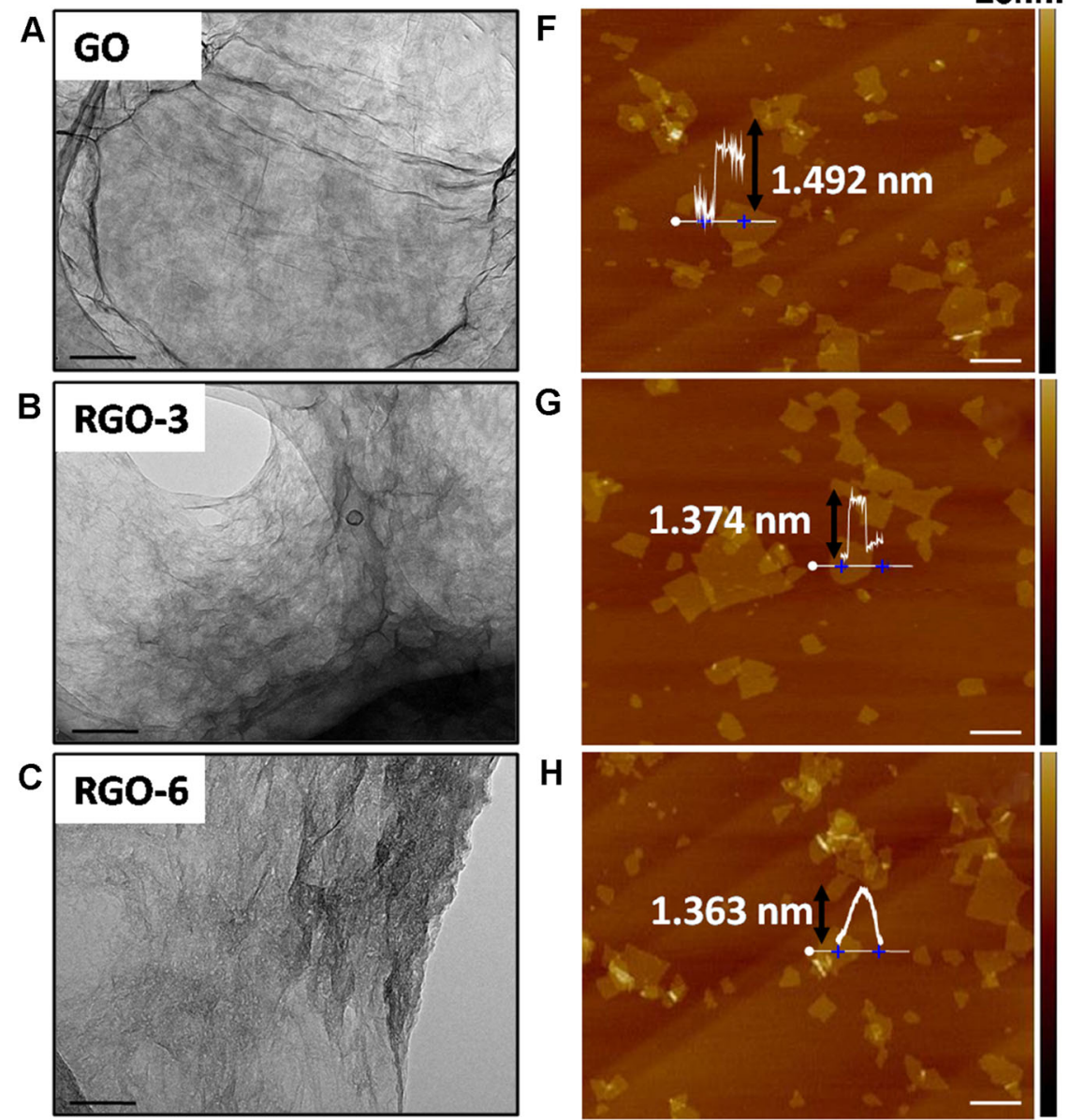

H
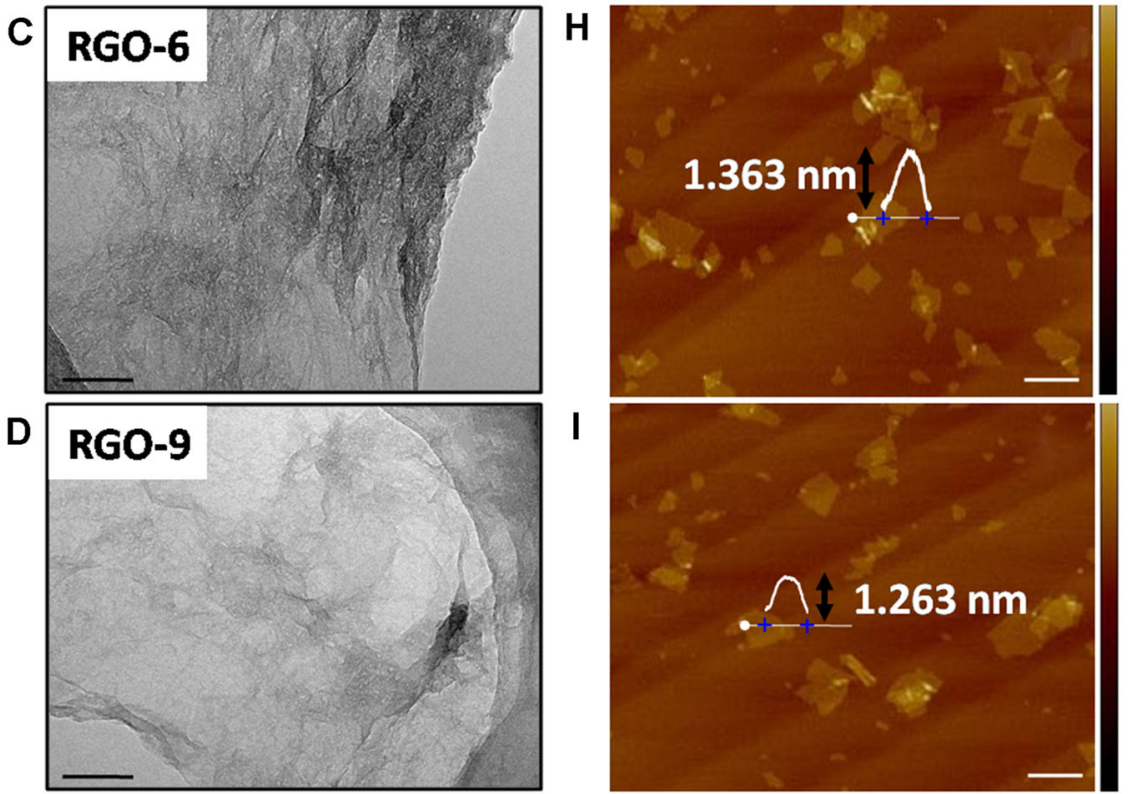

E

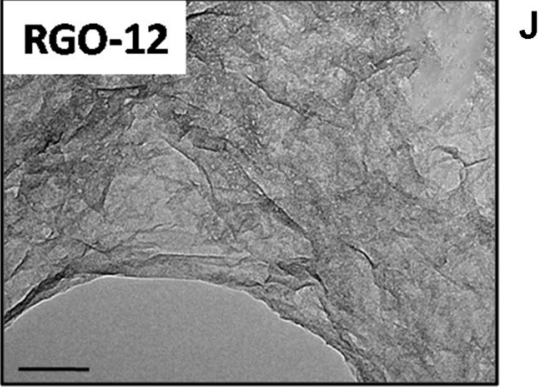

$J$

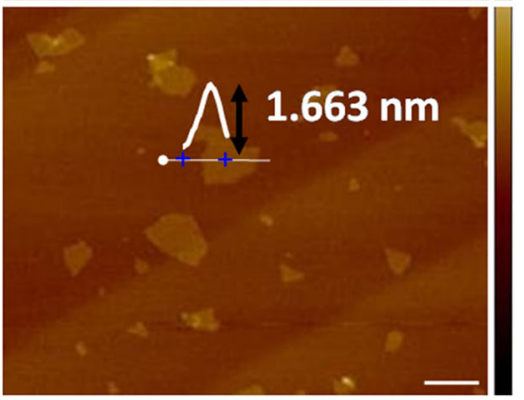

reduction of oxygen-containing functional groups caused few changes in the thickness and size of graphene, which are generally related to the genotoxicity of graphene derivatives.

\subsection{Cell viability}

The viability of ARPE-19 cells in the presence of GO or RGOs in the culture medium was determined by detecting 
the activities of intracellular dehydrogenases (CCK-8 assay). The cell viability of ARPE-19 cells with the addition of GO (up to $200 \mu \mathrm{g} / \mathrm{mL}$ ) was higher than $80 \%$, even after incubation for $72 \mathrm{~h}$ (Fig. 3A). However, the survival rates of ARPE-19 cells were significantly decreased with the reduction of $\mathrm{GO}$ to RGOs (Fig. 3B-E). Moreover, the RGOs-induced cell viability declined with increasing RGOs concentrations and culture times. Less than $10 \%$ cell viability was observed for the RGO-12 incubated cells after $72 \mathrm{~h}$. The cytotoxicity of GO and RGOs at different concentrations after $72 \mathrm{~h}$ of incubation is summarized in Fig. 3F, indicating the strong cytotoxicity of RGOs but the mild cytotoxicity of GO. The viability of ARPE-19 cells was further examined by live/dead staining assay (Fig. S1). ARPE-19 cells were incubated with $200 \mu \mathrm{g} / \mathrm{mL}$ GO or RGOs for $72 \mathrm{~h}$. Compared to the negative control, nearly $50 \%$ of cells died after incubation with GO, and over $80 \%$ of cells were killed by RGOs. These results confirmed the cell viability observed by the CCK- 8 assay.

\subsection{ROS level}

The cytotoxicity of carbon nanomaterials is always induced by oxidative stress, arising from ROS-dependent or ROSindependent pathways [16]. In a typical ROS-dependent pathway, the release of ROS is induced, resulting in oxidative stress. In a ROS-independent pathway, however, some materials (e.g., C60) could disturb or oxidize certain components in the cells, leading to the oxidative stress [17]. The ROS levels in ARPE-19 cells induced by GO or RGOs were therefore measured via the DCFH-DA method. As shown in Fig. 4, the ROS levels in ARPE-19 cells were significantly enhanced after incubation with RGOs, and the level of ROS production was directly correlated with the
Fig. 3 Cell survival rates of ARPE-19 cells incubated with various amounts of $\mathrm{GO}(\mathbf{A})$, RGO-3 (B), RGO-6 (C), RGO-9 (D), and RGO-12 (E) for 6, 12, 24,48 , and 72 h, respectively; $\mathbf{F}$ the summary of GO and RGOs incubated cells viability after $72 \mathrm{~h}$

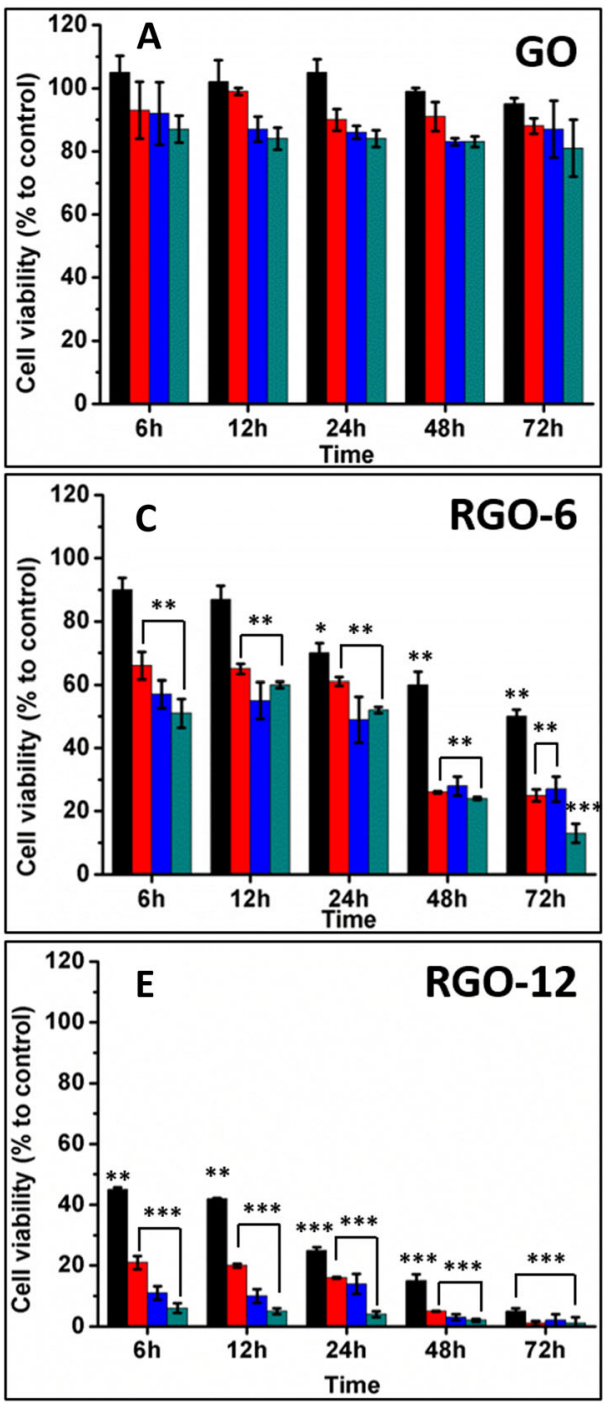

$10 \mu \mathrm{g} / \mathrm{mL}$ $50 \mu \mathrm{g} / \mathrm{mL}$ $\square 100 \mu \mathrm{g} / \mathrm{mL} \square 200 \mu \mathrm{g} / \mathrm{mL}$
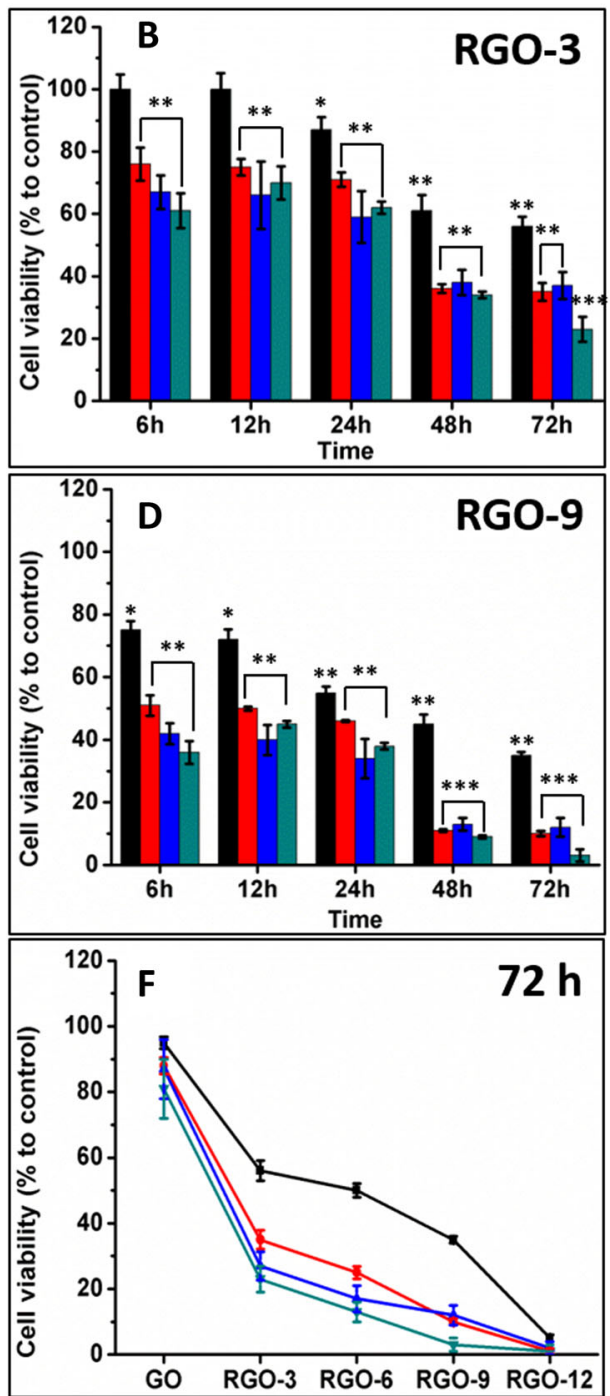
Fig. 4 ROS levels of ARPE-19 cells induced by various amounts of GO (A), RGO-3 (B) RGO-6 (C), RGO-9 (D), RGO12 (E) after different time and the summary of GO and RGOs incubated cells ROS levels after $72 \mathrm{~h}(\mathbf{F})$

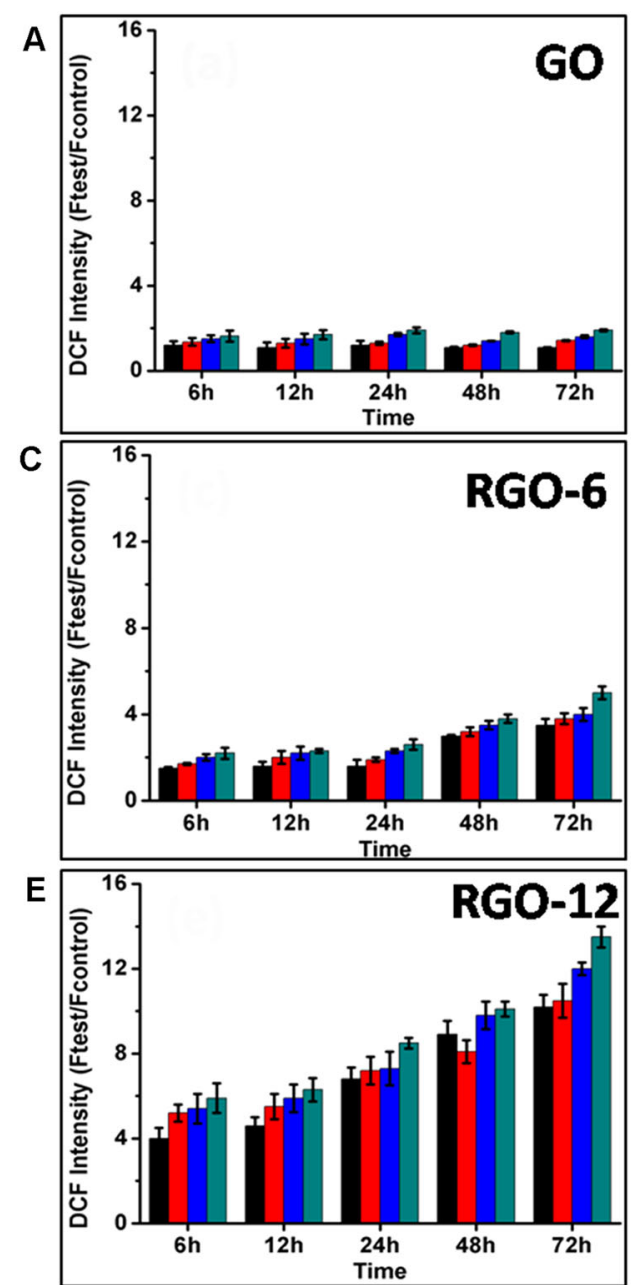

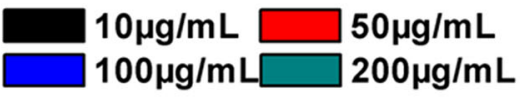
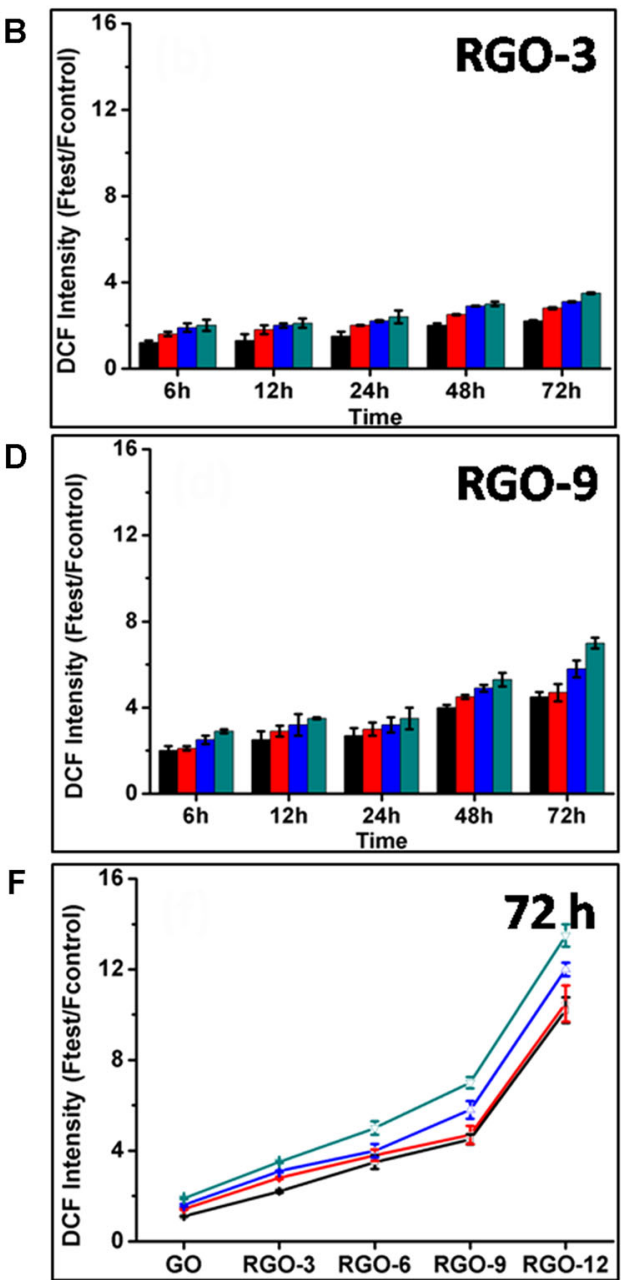

concentrations of RGOs and exposure time. In addition, the lower content of oxygen groups induced a greater ROS increase, which is consistent with the cell viability results. Therefore, the removal of oxygen groups from GO induced the ROS-dependent oxidative stress. The intracellular ROS level was also observed by fluorescence microscopy. As shown in Fig. S2, the intracellular ROS level was significantly increased by RGOs incubation.

\subsection{DNA damage}

DNA damage in of ARPE-19 cells induced by GO or RGOs after $24 \mathrm{~h}$ was assessed by the alkaline comet assay. Compared to the negative control (Fig. 5G), a 9\% DNA damage tail was visible in the GO-incorporated sample (Fig. 5A), suggesting that GO caused DNA damage in ARPE-19 cells. Significant DNA damage tails (16-18\%) were obtained when RGO-3 or RGO-6 was introduced (Fig. 5B, C), confirming that removal of oxygen-containing functional groups significantly increased the genotoxicity of GO. Moreover, $30 \%$ DNA damage tails were observed when the RGO-9 or RGO-12 was introduced to the cells (Fig. 5D, E), which was comparable to the positive control $(35 \%$ DNA tails) (Fig. 5f). The comet results suggested that both GO and RGOs induced the DNA damage in ARPE-19 cells after incubation for $24 \mathrm{~h}$. However, much greater amounts of DNA damage were observed for the RGOs, indicating that RGOs prepared from biocompatible reduction processes induced much more DNA damage than GO. Interestingly, we have demonstrated elsewhere that hydroxylfunctionalized graphene $(\mathrm{G}-\mathrm{OH})$ showed less than 5\% DNA damage tails in the comet test, even at the concentration of $100 \mu \mathrm{g} / \mathrm{mL}$ [7]. Comparing with the $9 \%$ tails obtained with $\mathrm{GO}, \mathrm{GOH}$ exhibited much lower genotoxicity. GO contains the unsaturated carbon-oxygen double bonds $(\mathrm{C}=\mathrm{O})$ that are not present in GOH. Das hypothesized that the reactive functional groups of GO interact with the macromolecules in cells and enhance the cytotoxicity [12]. However, on the 
Fig. 5 Fluorescence images of ARPE-19 cells during the Comet test after exposed to A GO, B RGO-3, C RGO-6, D RGO-9, E RGO-12, F the positive control, and $\mathbf{G}$ the negative control. Scale bar $=50 \mu \mathrm{m}$. H The percentages of tail DNA detected. I Western blot images of pi-p53 expression after exposure of ARPE-19 cells to GO or RGOs. J The relative amounts of pi-p53 to the control induced by GO or RGOs
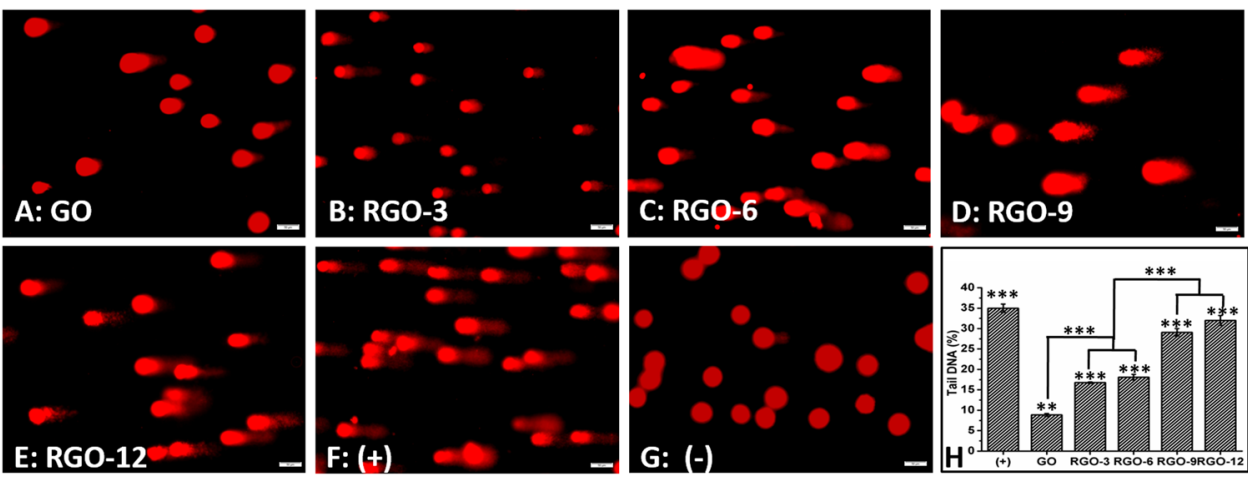

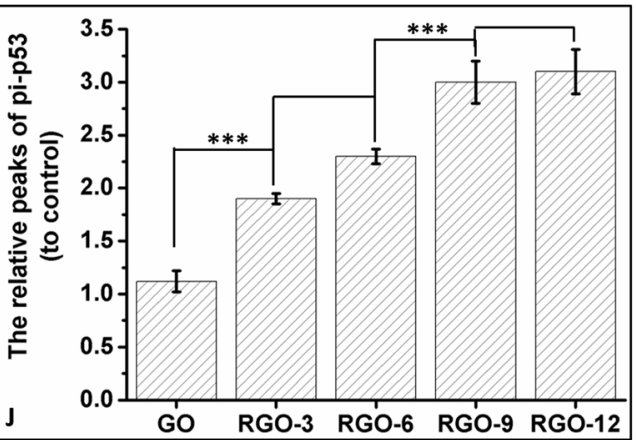

basis of our results, we speculate that the increased DNA damage of GO-treated cells might be attributed to the presence of unsaturated $\mathrm{C}=\mathrm{O}$ bonds, which are similar to some polyunsaturated lipids, facilitating the oxidation process and inducing further oxidative stress, which causes worse DNA damage [18]. However, the RGOs, especially RGO-6, RGO-9, and RGO-12, lost not only most of the $\mathrm{C}=\mathrm{O}$ (Fig. 1, XPS) but also a great amount of saturated $\mathrm{C}-\mathrm{O}$ bonds, which might enhance the compatibility of GO. Therefore, RGOs induced a significant ROS increase in the cells (Fig. 4F, ROS). In the report of Zhang et al. [13], the lower oxidation degree of GOs resulted in stronger indirect oxidative damage by promoting the conversion of $\mathrm{H}_{2} \mathrm{O}_{2}$ into ${ }^{\circ} \mathrm{OH}$. The direct oxidative abilities on cells of RGOs induced the DNA damage and finally decreased the cell viability.

DNA damage of GO or RGOs was further measured by the expression level of pi-p53 via Western blotting. pi-p53 is a DNA repair protein that remains inactive and has a short life time under normal conditions. p53 is activated by phosphorylation (pi-p53) when DNA is damaged. pi-p53 is stable and acts as a master guardian by triggering cell cycle arrest to provide time for the DNA repair [19]. Thus, the expression of pi-p53 is generally increased during the process of DNA damage. Our results clearly showed that the pi-p53 protein expression level increased after ARPE-19 cells were exposed to GO or RGOs (Fig. 5I). However, the expression of pi-p53 in RGO-treated cells was significantly increased compared to that in GO-treated cells. Furthermore, RGO-9- or RGO-12- treated cells expressed nearly
1.5 times more pi-p53 than the RGO-3- or RGO-6-treated cells (Fig. 5J). There was little statistical difference between RGOS-3 and RGO-6 or between RGO-9 and RGO- 12 . Western blot results further confirmed that both GO and RGOs caused DNA damage of ARPE-19 cells, while much more DNA damage was induced by the RGOs. These results were consistent with the comet results.

\section{Discussion}

Our preliminary results revealed detailed studies on the genotoxicity of GO and RGOs. For better biocompatibility results, RGOs with different oxygen contents were prepared by using biocompatible Na-citrate as the reductant. Successful removal of oxygen-containing functional groups from GO to RGOs was confirmed by UV-Vis, FTIR, and XPS measurements. The strong cytotoxicity of RGOs and mild cytotoxicity of GO were confirmed by a cell viability assay. Both GO- and RGOs-induced DNA damage was observed in the comet test and expression of pi-p53. Particularly worse DNA damage was induced by GO than by $\mathrm{GOH}$, suggesting possible roles of unsaturated $\mathrm{C}=\mathrm{O}$ in introducing DNA damage. Although both GO and RGOs displayed ROS-dependant genotoxicity, higher expression of pi-p53 was indicative of more serious DNA damage, which was obtained in the cells exposed to RGOs. The ROS generation test confirms that even small amounts of GO and RGOs can induce DNA damage, but GO shows much less genotoxicity than the RGOs, suggesting that saturated $\mathrm{C}-\mathrm{O}$ 
bonds are beneficial for better biocompatibility of GO. Therefore the oxygen-containing functional groups play essential roles in the genotoxicity of GBMs, in which the unsaturated $\mathrm{C}=\mathrm{O}$ bonds and saturated $\mathrm{C}-\mathrm{O}$ bonds might be attributed to opposite functions. Our results provide useful information for safe contact with GBMs and the potential for reducing the toxicity of GBMs via chemical modification.

Funding This study was supported by the Zhejiang National Nature Science Foundation (LY20C100002, LTQ20B010001, LQ21H120008), the Project of State Key Laboratory of Ophthalmology Optometry and Visual Science Wenzhou Medical University (K181001), Zhejiang Medical and Health Science and Technology (2018KY539), the Project for Extramural Scientists of State Key Laboratory of Agrobiotechnology (2020SKLAB6-5), and the Wenzhou Bureau of Science and Technology (Y2020249, Y2020221, Y20180058)

Author contributions Conceptualization: YQ, MY, LQ; methodology: $\mathrm{XL}, \mathrm{ZW}, \mathrm{LO}, \mathrm{WX}, \mathrm{YH}$; formal analysis and investigation: YQ, WS, XL, ZW, LO, WX, LC, YH, MY, LQ; writing-original draft preparation: YQ, XL, ZW; writing - review and editing: MY, LQ; funding acquisition: WS, XL, LC, YM, LQ; resources: LQ; supervision: YQ, MY, LQ.

\section{Compliance with ethical standards}

Conflict of interest The authors declare no competing interests.

Publisher's note Springer Nature remains neutral with regard to jurisdictional claims in published maps and institutional affiliations.

Open Access This article is licensed under a Creative Commons Attribution 4.0 International License, which permits use, sharing, adaptation, distribution and reproduction in any medium or format, as long as you give appropriate credit to the original author(s) and the source, provide a link to the Creative Commons license, and indicate if changes were made. The images or other third party material in this article are included in the article's Creative Commons license, unless indicated otherwise in a credit line to the material. If material is not included in the article's Creative Commons license and your intended use is not permitted by statutory regulation or exceeds the permitted use, you will need to obtain permission directly from the copyright holder. To view a copy of this license, visit http://creativecommons.org/licenses/by/4.0/.

\section{References}

1. Yan L, Zhao BX, Liu XH, Li X, Zeng C, Shi HY, et al. Aligned nanofibers from polypyrrole/graphene as electrodes for regeneration of optic nerve via electrical stimulation. ACS Appl Mater Interfaces. 2016;8:6834-40. https://doi.org/10.1021/acsami.5b12843.

2. Yang M, Liang YL, Gui QY, Chen J, Liu Y. Electroactive biocompatible materials for nerve cell stimulation. Mater Res Express. 2015;2. https://doi.org/10.1088/2053-1591/2/4/042001.

3. Cheng RM, Zou RT, Ou SJ, Guo R, Yan RY, Shi HY, et al. Graphene oxide complex as a $\mathrm{pH}$-sensitive antitumor drug. Polym Chem. 2015;6:2401-6. https://doi.org/10.1039/c5py00047e.
4. Dreyer DR, Park S, Bielawski CW, Ruoff RS. The chemistry of graphene oxide. Chem Soc Rev. 2010;39:228-40. https://doi.org/ 10.1039/b917103g.

5. Sydlik SA, Jhunjhunwala S, Webber MJ, Anderson DG, Langer R. In vivo compatibility of graphene oxide with differing oxidation states. ACS Nano. 2015;9:3866-74. https://doi.org/10.1021/a csnano. 5 b01290.

6. Hu XG, Ouyang SH, Mu L, An J, Zhou Q. Effects of graphene oxide and oxidized carbon nanotubes on the cellular division, microstructure, uptake, oxidative stress, and metabolic profiles. Environ Sci Technol. 2015;49:10825-33. https://doi.org/10. 1021/acs.est.5b02102.

7. Lin M, Zou R, Shi H, Yu S, Li X, Guo R, et al. Ocular biocompatibility evaluation of hydroxyl-functionalized graphene. Mater Sci Eng C. 2015;50:300-8. https://doi.org/10.1016/j.msec. 2015.01.086.

8. Yan L, Wang YP, Xu X, Zeng C, Hou JP, Lin MM, et al. Can graphene oxide cause damage to eyesight? Chem Res Toxicol. 2012;25:1265-70. https://doi.org/10.1021/Tx300129f.

9. Liao KH, Lin YS, Macosko CW, Haynes CL. Cytotoxicity of graphene oxide and graphene in human erythrocytes and skin fibroblasts. ACS Appl Mater Interfaces. 2011;3:2607-15. https:// doi.org/10.1021/am200428v.

10. Chang Y, Yang S-T, Liu J-H, Dong E, Wang Y, Cao A, et al. In vitro toxicity evaluation of graphene oxide on A549 cells. Toxicol Lett. 2011;200:201-10.

11. Chen Q, Tian S, Zhu J, Li KT, Yu TH, Yu LH, et al. Exploring a novel target treatment on breast cancer: aloe-emodin mediated photodynamic therapy induced cell apoptosis and inhibited cell metastasis. Anticancer Agents Med Chem. 2016;16:763-70. https://doi.org/10.2174/1871520615666150821093323.

12. Das S, Singh S, Singh V, Joung D, Dowding JM, Reid D, et al. Oxygenated functional group density on graphene oxide: its effect on cell toxicity. Part Part Syst Charact. 2013;30:148-57. https:// doi.org/10.1002/ppsc.201200066.

13. Zhang WD, Yan L, Li M, Zhao RS, Yang X, Ji TJ, et al. Deciphering the underlying mechanisms of oxidation-state dependent cytotoxicity of graphene oxide on mammalian cells. Toxicol Lett. 2015;237:61-71. https://doi.org/10.1016/j.toxlet.2015.05.021.

14. Ryoo SR, Kim YK, Kim MH, Min DH. Behaviors of NIH-3T3 fibroblasts on graphene/carbon nanotubes: proliferation, focal adhesion, and gene transfection studies. ACS Nano. 2010;4:6587-98. https://doi.org/10.1021/nn1018279.

15. Qi L, Lv X, Zhang T, Jia P, Yan R, Li S, et al. Cytotoxicity and genotoxicity of bacterial magnetosomes against human retinal pigment epithelium cells. Sci Rep. 2016;6:26961. https://doi.org/ 10.1038/srep26961.

16. Liu SB, Zeng TH, Hofmann M, Burcombe E, Wei J, Jiang RR, et al. Antibacterial activity of graphite, graphite oxide, graphene oxide, and reduced graphene oxide: membrane and oxidative stress. ACS Nano. 2011;5:6971-80. https://doi.org/10.1021/ nn202451x.

17. Lyon DY, Brunet L, Hinkal GW, Wiesner MR, Alvarez PJJ. Antibacterial activity of fullerene water suspensions (nC60) is not due to ROS-mediated damage. Nano Lett. 2008;8:1539-43.

18. German JB. Food processing and lipid oxidation. Adv Exp Med Biol. 1999;459:23.

19. Vuong L, Conley SM, Al-Ubaidi MR. Expression and Role of p53 in the retina. Investig Ophthalmol Vis Sci. 2012;53:1362-71. https://doi.org/10.1167/iovs.11-8909. 